\title{
Prototipos mexicanos y el conflicto migratorio en el filme Coco, de Walt Disney.
}

Mexican prototypes and the migratory conflict in the film Coco, by Walt Disney.

DOI: $10.32870 /$ sincronia.axxv.n79.25a21

\section{Arturo Morales Campos}

Facultad de Letras. Universidad Michoacana de San Nicolás de Hidalgo (MÉXICO)

CE: arturo moralescampos@yahoo.com.mx / ID ORCID: 0000-0003-0939-8011

\section{Esta obra está bajo una Licencia Creative Commons Atribución-NoComercial 4.0 Internacional}

Recibido: $18 / 02 / 2020$

Revisado: 03/10/2020

Aprobado: 03/11/2020

\section{RESUMEN}

En el presente trabajo, analizaremos un texto fílmico que, supuestamente, está dirigido a un público infantil, se trata de la reciente obra Coco (2017), de los directores Lee Ulrich y Adrián Molina. Nuestro objetivo principal es el de examinar determinadas estructuras nocionales o marcas semánticas en el filme, cuya ideología subyacente se refiere al fenómeno migratorio que se registra a largo de la frontera entre México y Estados Unidos. Esas marcas semánticas, por su constante presencia en otros textos y situaciones, se asumen como prototípicas. En consecuencia, el filme en cuestión, lejos de hacer un "homenaje" a la cultura mexicana, estigmatiza determinadas prácticas de ese ambiente humano. El fuerte aparato publicitario en el que la compañía cinematográfica Walt Disney soporta este producto permite la "naturalización" de dicha visión prototípica. Utilizaremos algunas propuestas teóricas de la sociosemiótica y del análisis crítico del discurso.

Palabras Clave: Signo hegemónico. Núcleo semántico. Identidad. Frontera. Ilegal. 


\section{ABSTRACT}

In the present paper, we propose to analyze a filmic text that, supposedly, was created for a children's audience, it is the recent Walt Disney's work Coco (2017), by directors Lee Ulrich and Adrian Molina. We will be guided by sociosemiotic notions and the critical analysis of discourse in order to study certain semantic marks related to the migratory phenomenon that is recorded along the border between Mexico and the United States. These semantic marks, due to their constant presence in other texts and situations, are assumed to be prototypical. According to the above, far from "paying tribute" to Mexican culture, Coco stigmatizes certain practices of that culture. The "media machine" with which Disney supports this product allows the "naturalization" of such prototypical vision.

Keywords: Hegemonic sign. Semantic nucleus. Identity. Border. lillegal.

\section{Introducción}

Es común pensar que las obras artísticas dirigidas a un público infantil carecen de ideologías políticas, religiosas, raciales, etc., o que persiguen objetivos "neutrales", los cuales inciden en ámbitos de la diversión, de valores prestigiosos, educativos o, en todo caso, que dichas obras están cubiertas por un velo de inocencia.

Algunos ejemplos que desdicen radicalmente lo anterior podrían ser varias de las caricaturas que aparecieron en Estados Unidos a partir de la Segunda Guerra Mundial. Esos productos, de forma explícita y desde una posición nacionalista en extremo, ridiculizan y/o vencen tanto enemigos japoneses como alemanes. Citaremos tres realizaciones, que creemos representativas, solamente para dar una idea: de Paramount Pictures, Japoteurs (1942) (juego de palabras en inglés que transforma "saboteurs", o "saboteadores" en español, para estigmatizar a los japoneses como enemigos mortales) en la que Superman destruye un enorme y poderoso avión japonés, diseñado para bombardear la nación estadounidense; de Warner Brothers, Tokio jokio (1943) (“jokio" es una alteración de "joke", o "broma" en español) es una sátira racista que hace pasar a los japoneses como seres faltos de razón; finalmente, de Walt Disney, The spirit of '43 (1943) (El espíritu del 43 en 
español), aquí, Donald invita a la sociedad norteamericana a pagar sus impuestos debidamente con el fin de incrementar la producción de armamento y, en consecuencia, lograr el triunfo en la guerra, de esta forma, la continuidad de la libertad en ese país estaría garantizada. Los anteriores casos fueron significativos en cuanto a la construcción del proyecto que sentaría las bases para la conformación de la imagen de aquel pueblo como nación libertadora, modelo de modernidad y guardiana de la paz mundial.

La reputación general que tiene la compañía estadounidense Walt Disney no podría conciliarse con la de, por ejemplo, ser un auténtico aparato ideológico de estado. La mercadotecnia que gira en derredor de cada uno de sus productos, además de los tonos cómicos y sentimentales que aparecen dentro de ellos, son factores fundamentales que no permiten encontrar, fácilmente, manipulación ideológica alguna dentro de dichos productos. Armand Mattelart (1979), referencia obligada (junto con Ariel Dorfman, 2013) en cuanto a análisis con una visión crítica, nos muestra ciertas estrategias textuales utilizadas por diversos programas televisivos, cómics y películas que, bajo una máscara "educativa" y/o "infantil" (como Plaza Sésamo), han servido para promover visiones de mundo a favor, principalmente, de los intereses del poder político-económico estadounidense.

En forma paradójica, los mitos de Disney sobre la inocencia de sus personajes adultos con cuerpo de niño entran, oficialmente y de lleno, en las aulas, que dejan de pertenecer exclusivamente a la austera escuela y se ensanchan según la autopublicidad de sus promotores hasta cobrar las dimensiones del "mundo". (Mattelart, 1979, p. 93).

En otro lugar, Ariel Dorfman y el mismo Mattelart señalan un par de recursos comunes utilizados por la nombrada compañía Disney, a saber, estigmas culturales y prototipos o modelos humanos altamente generalizantes, elementos muy claros en nuestro objeto de estudio.

Es indudable que Aztecaland es México: todos los prototipos del "ser" mexicano de tarjeta postal se guarecen aquí. Burros, siestas, volcanes, cactus, sombreros enormes, ponchos, serenatas, machismo, indios de viejas civilizaciones. No importa que el nombre sea 
otro, porque reconocemos y fijamos al país de acuerdo con esa tipicidad grotesca. El cambio de nombre, petrificando el embrión arquetípico, aprovechando todos los prejuicios superficiales y estereotipos acerca del país, permite Disneylandizarlo sin trabas. (Dorfman, 2013, p. 69)

En lo que a nuestro trabajo respecta, es, en principio, ese marcado uso de prototipos ${ }^{1}$ mexicanos en el filme Coco, los mismos que se encuentran dentro de un par de estructuras textuales que denominamos como "núcleos semánticos". La presencia de dichos prototipos nos abre la puerta hacia otros niveles de análisis más profundos. A su vez, al interior de aquellos núcleos semánticos, aparecen nociones (connotaciones) articuladas a un signo hegemónico, la frontera, elemento significativo éste que nos remite al fenómeno de la migración mexicana con destino al vecino país del norte. En consecuencia, la noción de "frontera ideológica" será una herramienta teórica fundamental en cuanto a demostrar la anterior argumentación.

La estructura general de nuestro trabajo es la siguiente. El primer apartado abordará los presupuestos teóricos base de los que partiremos. El segundo y tercer segmentos presentarán las connotaciones torales de los dos mundos en los que se desarrolla la diégesis de nuestro texto cinematográfico, los cuales, correspondientemente, son: el "Mundo de los Vivos" o "Mundo de la mismidad" y el "Mundo de los Muertos" o "Mundo de la otredad". El cuarto estará destinado a analizar uno de los signos hegemónicos determinantes del filme, la ya mencionada frontera, espacio en el que se registran tanto prácticas discursivas y no-discursivas que nos remiten, a la vez, al conflicto migratorio como a estigmatizar una serie de costumbres "prototípicas" 2 adjudicada a la cultura mexicana y, en adición, a la imposición de un modelo ideológico individualista propio del estilo de vida estadounidense. ${ }^{3}$ No resulta una casualidad, pues, que el actual régimen

\footnotetext{
1 Entendemos los prototipos como modelos construidos a partir de determinadas características físicas y/o de personalidad de uno o un grupo de individuos que, supuestamente, representa a una colectividad humana específica.

${ }^{2}$ Utilizamos este término y sus derivados como una herramienta conceptual, mas no creemos que pueda existir un modelo cultural (humano y/o material) que pueda representar toda la complejidad de una comunidad.

${ }^{3}$ Esta afirmación, paradójicamente, parece ser una postura prototípica. En las conclusiones, estaremos aclarando éste y otros casos similares.
} 
gubernamental del país vecino coloque como uno de sus temas de discusión las relaciones con México en un nivel de seguridad nacional. Esta situación se corresponde, en gran medida, con las circunstancias sociohistóricas en las que emerge el filme que, como podremos darnos cuenta, gran parte de ellas aparece modelizada (adaptada) y transcripta por el mismo texto.

\section{Presupuestos teóricos}

Existen diversas propuestas teóricas de corte sociosemiótico. Nosotros seguiremos algunas que encabeza Edmond Cros (1986), las cuales reciben el nombre de sociocrítica, y que complementaremos con las nociones de "núcleos semánticos" y "signos hegemónicos". Como complemento, nos valdremos de la postura del análisis crítico del discurso.

\section{a) Elementos básicos de la sociosemiótica}

Bajo el anterior marco, presentamos dos lineamientos generales que caracterizan a la mayoría de los productos culturales, en los que incluimos a los textos unicódigo (como un cuento) o pluricódigo (como un filme):

1) todo texto, como elemento testimonial, tiende a reproducir, de variadas formas, rastros de ideologías dominantes y/o contrahegemónicas comunes al momento de su producción;

2) la emisión de prácticas discursivas y/o no-discursivas por cualquier individuo, perteneciente a una cultura determinada, difícilmente será considerada como políticamente "desinteresada" o "neutral".

Las anteriores premisas nos permiten hablar más bien de una intención textual y no de una intención del autor. Para explicar esto, seguimos a Cros cuando se refiere al discurso como instrumento social: "en la medida en que el discurso establece relaciones entre instituciones sociales, procesos económicos y sociales, formas de comportamiento, sistemas de normas, técnicas, tipos de clasificaciones, modos de caracterización, lo percibimos como práctica social" o práctica 
discursiva, la cual "implica siempre una socialidad (sic.) del acto del habla y una relación profunda con la historia" (1986, p. 59). Por lo tanto, la sociosemiótica se interesa por las relaciones que mantienen determinadas estructuras textuales con determinadas estructuras sociales, debido a la importancia de las circunstancias sociohistóricas que privan en el momento de emergencia del texto. Por nuestra parte, extendemos las anteriores características discursivas a las prácticas nodiscursivas.

\section{b) La postura del análisis crítico del discurso}

El análisis crítico del discurso es una disciplina que se encarga de estudiar "las relaciones de dominación, discriminación, poder y control, tal como se manifiestan a través del lenguaje" (Wodak, 2003, p. 19). Esta postura implica, entre otras cosas, que las prácticas discursivas, comúnmente, contienen rastros de diversas ideologías (dominantes o no). En consecuencia y por lo dicho acerca del carácter social del discurso, no siempre somos plenamente conscientes de reproducir dichas referencias ideológicas y, además, estas mismas, en varias ocasiones, se asumen como verdades incuestionables, de tal forma que parecen ser hechos "naturales" o "normales". Es este, fundamentalmente, el problema que trata de desvelar el análisis crítico del discurso: la naturalización de dichas posturas ideológicas:

Según este punto de vista, las estructuras dominantes estabilizan las convenciones y las convierten en algo natural, es decir, los efectos del poder y de la ideología en la producción de sentido quedan oscurecidos y adquieren formas estables y naturales: se los considera como algo «dado». (2003, p. 20)

\section{c) Núcleos semánticos y signos hegemónicos}

Entendemos el texto como un entramado de signos íntimamente relacionados entre sí. Dichos signos pueden pertenecer a diversos códigos: musicales, lingüísticos, sonoros, visuales, gestuales, proxémicos, etc. Los textos fílmicos están compuestos por varios de esos códigos, lo que los convierte en textos pluricódigo. En cualquier tipo de texto, la carga semántica puede ser distinta en 
cada uno de los signos que lo componen. A los que cuenten con mayor carga los reconoceremos como signos hegemónicos.

Una determinada "región" textual (una escena, un párrafo, un capítulo, en fin) reúne signos de diferente carga semántica. Cuando una asociación sígnica de ese tipo nos remite a connotaciones fundamentales que aparecerán, en diferentes momentos, a lo largo del texto, estamos frente a un núcleo semántico.

Gracias a la coherencia global que aporta el fuerte entramado sígnico, un núcleo semántico será capaz de contener rastros del significado total del texto. De ahí la importancia de su análisis.

\section{d) Frontera ideológica}

Una frontera puede entenderse como un espacio o un ambiente en el que se registra determinado problema identitario bajo diversas formas; "cabe subrayar que es un concepto que alude a un espacio, ya sea geográfico, físico, ideal, imaginario o virtual" (Crespo, 2014, p. 16; las cursivas son textuales). Con base en el anterior marco, la distancia entre lo espacial y lo ideológico no tiene lugar, por ello es que decimos que el término implica conflictos de orden identitario, es decir, enfrentamientos (no necesariamente violentos) entre la mismidad y la otredad. Explicamos.

La frontera puede ser de individuo a individuo, de familia a familia, de barrio a barrio, de profesión a profesión, de estado a estado, de país a país, etc. Así, de un lado de una frontera territorial, por ejemplificar, se sitúa el espacio de la mismidad que reúne a un "nosotros" ideal, ${ }^{4}$ del lado opuesto, aparecerá la contraparte: la otredad que se instala como la diferencia, lo extraño, lo ajeno, lo problemático, la amenaza. Cada espacio re-creará un conjunto de prácticas culturales (discursivas y/o no-discursivas con determinada carga ideológica) que se piensan como únicas, como distintivas: "En tal caso, dichas prácticas se consideran objetivas y universales [en cada uno de los espacios]. Las prácticas del propio clan pueden parecer absolutas y racionales; las prácticas diferentes, en cambio, pueden parecer bárbaras e irracionales" (Churchland, 2012, p. 149). Por

\footnotetext{
${ }^{4}$ En cuanto a esa ilusión colectiva de la mismidad, recomendamos Anderson (1997).
} 
ende, traspasar la frágil línea entre un lado y otro no es una situación tersa, sino una transgresión que puede causar graves conflictos entre grupos humanos.

En adición, los elementos diferenciadores que otorga el constructo identitario a un individuo son de orden colectivo y permiten una posición ideológica ante los elementos del Universo (lo que denominamos como realidad: lo objetivo y lo subjetivo). De esta forma, las prácticas culturales, cualquiera que sea el lado desde donde se observe, tienden a ser genéricas y, por lo tanto, susceptibles de entenderse como prototípicas.

Finalmente, no resulta vano indicar la diferencia semántica entre los conceptos español "frontera" e inglés "border". Como dimos a entender, el primero indica un límite (físico e ideológico) entre, al menos, dos espacios; el segundo tiene una acepción que refiere el final, el borde ("edge") de algo sin que, necesariamente, la otredad continúe del otro lado. Más adelante, esto tendrá una relevancia importante.

\section{El mundo de la mismidad}

Miguel Rivera, el niño protagonista del filme, vive en un pueblo mexicano, llamado Santa Cecilia, con su familia de once miembros; ambos, pueblo y familia, nos muestran características (signos) que podríamos asociar como parte de un mundo tradicional, mismo que contiene ciertos rasgos adjudicados, genéricamente, a la cultura mexicana: ${ }^{5}$ calles empedradas y decoradas con papel picado de colores, casas de tejas con pisos de tierra, vendimia informal en las calles (principalmente "cempasúchil"; flor de color anaranjado cuyo nombre náhuatl significa "flor de muertos" en español, es por ello que se usa para adornar los altares), objetos arrumbados (tejas, láminas, tablas, ladrillos, en fin) en patios y calles, trabajos familiares no profesionales (compostura de zapatos, músicos callejeros), varios miembros consanguíneos de diversas generaciones que comparten solidariamente la misma casa, romanticismo, melomanía, comida tradicional, etc.

Debido a una experiencia negativa que tuvo la tatarabuela de Miguel, Ilamada mamá Imelda, la música está prohibida en su hogar: el esposo de esa mujer fue un músico y actor famoso, Ernesto

\footnotetext{
${ }^{5}$ Ver nota uno.
} 
de la Cruz, que abandonó todo por buscar el éxito. Paradójicamente, Miguel quiere ser músico. (Notemos que el nombre del pueblo coincide con el de la santa patrona de la música.) La fiesta del Día de los Muertos envuelve toda la diégesis ${ }^{6}$ del texto cinematográfico. Al final, después de un extraño viaje al Mundo de los Muertos, el chico logra su sueño.

El filme da principio con una breve introducción (paratexto), ${ }^{7}$ en la que la voz en off de Miguel nos cuenta parte de su vida, la cual, según él, está envuelta en un hechizo. En ese breve espacio, la narración nos revela el doble rompimiento mencionado: el matrimonial de Ernesto de la Cruz y el que llevó a cabo la esposa cuando, por generaciones, prohíbe la música en la casa. En consecuencia, la mujer se dedica al negocio de la reparación de calzado, tradición que aún se practica en el presente de las acciones. Esa labor, fuente única de ingresos, une a todos los miembros de la familia. La línea matriarcal, desde el doble rompimiento, caracteriza a ese grupo humano.

El inicio de la díégesis (Capítulo 1) nos marca el Día de los Muertos, como si fuera un día normal: por la mañana, todos los familiares se congregan en la zapatería para trabajar. Miguel sale a la calle con su cajón de lustrador de calzado en busca de clientes. El chico pasa por algunas calles del pueblo hasta llegar a la plaza principal. Las imágenes de fondo son altamente significativas: la pintura de las casas está visiblemente deteriorada; las tejas presentan irregularidades; una camioneta pick-up vieja; un hombre desocupado, parado en una esquina y recargado en la pared con los brazos cruzados; algunos grupos musicales de tipos norteño y mariachi; puestos de mercado; en fin. Sin embargo, hay una escena que nos parece relevante en demasía. Miguel está muy cerca de la plaza principal y toca, como si fueran percusiones, varios alebrijes, ${ }^{8}$ hechos de madera, de uno de los puestos. Detrás de él, se exhibe la fachada de una casa cuyas tejas están, como ya hicimos mención, notoriamente estropeadas; un conjunto de tablas viejas y unos tubos

\footnotetext{
${ }^{6}$ La diégesis se refiere a la secuencia de acciones o a la historia en un texto narrativo.

${ }^{7}$ Llamamos paratextuales a aquellos elementos que no pertenecen a la trama textual principal. En un filme, algunos de ellos son: los créditos (iniciales y finales), el diseño de la portada, el nombre de la compañía fílmica, determinada información introductoria, etc.

${ }^{8}$ Figuras artísticas de animales fantásticos y coloridos (generalmente de madera) que se elaboran en el estado de Oaxaca (al suroeste de México).
} 
aparecen en un extremo; la constante de la pintura deteriorada; al final del puesto, hay un bote de basura que muestra, con mucha claridad, suciedad en su superficie; de ese bote, sale un perro xoloitzcuintle callejero (perro tradicional mexicano), llamado Dante, quien será compañero del niño.

Antes de proseguir, nos gustaría señalar la importancia del nombre que tiene el perro en el filme, puesto que nos remite a la obra de Dante Alighieri, La Divina Comedia, escrita por partes en las primeras décadas del siglo XIV. Dante, como personaje principal del texto literario, cruza por diferentes regiones del Infierno, el Purgatorio y el Paraíso. En cada una de esas partes, Dante estará acompañado por una persona diferente que juega el papel de guía. En el Infierno, Virgilio, el poeta romano, será el primero; en el Purgatorio, Sordello, trovador también romano, será el segundo; finalmente, en el Paraíso, Beatriz, figura amada de Dante, lo llevará por esta última sección.

Ahora bien, Dante, el perro amigo de Miguel cumple, de alguna manera, igualmente el rol de guía en el Mundo de los Muertos. En este sentido, estamos hablando de un fenómeno de intertextualidad. Como sabemos, toda intertextualidad conlleva una deconstrucción que, en la película, sucede, a grandes rasgos, en dos niveles. El más general reside en una transcodificación, es decir, un cambio de código: la novela, cifrada en un código lingüístico, pasa parte de su materia significante al texto receptor (el filme), cifrado éste en varios códigos, a saber, visual, sonoro, musical, lingüístico, etc. El nivel más específico se concentra, precisamente, en el personaje canino quien lleva el nombre del personaje principal en la novela, pero, ahora, es un guía. La anterior deconstrucción se explica mediante un aspecto dentro de la tradición mítica azteca: el xoloitzcuintle es quien conduce las almas al Mictlán o inframundo. ${ }^{9}$

Después de la anterior digresión, pasemos a nuestro objeto de estudio. Las nociones constantes de desorden, descuido e informalidad nos remiten a una connotación central, a saber, pobreza. No olvidemos las características de la familia: su labor informal, su casa rústica y el elevado número de miembros (la madre de Miguel, en adición, espera un hijo además de los dos que ya tiene). Todas las personas del pueblo comparten las mismas marcas semánticas, es, por tanto,

\footnotetext{
${ }^{9}$ La tradición cristiana nombró este microcosmos como el Infierno, no obstante, la visión indígena original es el de un espacio creador donde moran dioses de la muerte y la resurrección.
} 
explícita una homogeneización. Aunado a lo anterior, existe la noción constante de familia, de la que se desprenden varios rastros discursivos que connotan unidad, tradición, guía, respeto. Veamos algunas frases alusivas. La abuela le dice a Miguel (Capítulo 2), frente al altar familiar: "Todo es [el colocar el altar] para que la familia se reúna [...] Ser parte de esta familia indica apoyar siempre a esta familia". Por otro lado, su padre le comunica la noticia (Capítulo 3), también frente al altar, de que la abuela ha decidido que debe dejar de lustrar zapatos y, así, continuar con la tradición familiar, en consecuencia, ya podrá trabajar en la zapatería después de la escuela. El padre expresa: "Tienes a tu familia para guiarte. Tú eres un Rivera y un Rivera ¿es...?", responde el chico con molestia: "Un zapatero hasta los huesos". ${ }^{10}$

Consideramos, pues, que, si Miguel se dedicara a la música, estaría cometiendo una grave transgresión que atentaría contra los valores familiares, es decir, las concentradas en las connotaciones correspondientes que acabamos de presentar. De hecho, ya está incurriendo en una infracción al tocar, a escondidas, su guitarra. Si resumimos, el "respeto" a las reglas familiares, por un lado, y la "transgresión" de esas mismas normas, por el otro, serían las connotaciones que configurarían un par dicotómico de signos hegemónicos cuya carga semántica es altamente representativa en esta primera parte del texto fílmico. Finalmente, las escenas abordadas conforman el primer núcleo semántico de nuestro análisis.

\section{El mundo de la otredad}

Por la tarde del mismo Día de los Muertos, Miguel quiere participar en un concurso de músicos en la plaza principal (Capítulo 3). Un poco antes, de manera accidental, rompe el cristal que protege la fotografía del altar en la que aparecen su tatarabuela, su bisabuela Coco (de niña) y su tatarabuelo. Este hombre lleva puesto un traje de mariachi, pero, por haber abandonado a su familia, la abuela arrancó la parte de su cara. Miguel recoge la fotografía y descubre que hay una sección oculta detrás del marco en la que, aparentemente, se revela la identidad fragmentada del tatarabuelo: el

\footnotetext{
${ }^{10}$ Aclaramos que presentamos transcripciones de voces y diálogos que hemos comparado con la versión original en inglés. Cuando lo creamos necesario, haremos la distinción de una variante que se utilizó en español.
} 
hombre sin rostro empuña con la mano izquierda la emblemática guitarra de Ernesto de la Cruz. Gracias a la fuerte insistencia acerca de la tradición familiar, Miguel se cree heredero del legado musical de su ancestro. El niño va a su escondite donde guarda una guitarra hechiza similar a la que distingue a de la Cruz, discos, imágenes y videos del artista, entre otras cosas. Toma la guitarra y, con entusiasmo, comunica su descubrimiento al resto de la familia. La abuela, encolerizada, destruye el instrumento. Miguel sale de su casa, evidentemente enojado, después de haber renegado contra la tradición de los suyos y del altar familiar. Llega a la plaza y trata de participar en el concurso (Capítulo 4), pero debe tener una guitarra. Se dirige, después de pedir prestada infructuosamente una a diferentes músicos participantes, hacia la estatua de su tatarabuelo y le pregunta: "¿Qué se supone que debo hacer"? La cara del chico se ilumina por el reflejo de los fuegos artificiales de fondo y aparece, a los pies de Ernesto de la Cruz, la frase que hizo famoso al personaje: "Seize your moment!" (“iAprovecha tu momento!” en español). Miguel, decidido, visita el mausoleo dedicado a su tatarabuelo. En el interior, como parte de un altar, se encuentra la simbólica guitarra de la estrella. Miguel la toma y, en ese momento, se transforma en una especie de espectro que nadie puede ver, excepto Dante y los muertos (también invisibles para los vivos); estos últimos han llegado a alimentarse de las ofrendas que les han colocado sus respectivos familiares. De esta forma, el niño tiene la facilidad de visitar el Mundo de los Muertos.

Ese nuevo microcosmos presenta estructuras, social y física, diferentes a la del Mundo de los Vivos. Asimismo, todos sus habitantes son esqueletos animados, no obstante, conservan rasgos e indumentaria que se han colocado como prototípicos de determinados grupos sociales mexicanos: los hombres con un gastado sombrero de palma, huaraches o botas vaqueras, pañoleta al cuello, pantalón de mezclilla o atuendo de mariachi; las mujeres, de trenzas, ataviadas como la famosa catrina de José Guadalupe Posada. ${ }^{11}$ Al igual que en el Mundo de los Vivos, se distingue un tono de voz norteño en hombres y mujeres.

\footnotetext{
${ }^{11}$ Figura de un esqueleto femenino ataviado con ropa elegante común entre las clases privilegiadas de finales del siglo XIX. Guadalupe Posada (1852-1913) fue un famoso caricaturista, ilustrador y grabador mexicano.
} 
La manera de acceder a ese ambiente es por medio de varios puentes, colocados en diferentes niveles y forrados de pétalos de cempasúchil. Los puentes de los niveles inferiores llevan hacia unas construcciones piramidales de estilo precolombino que, a su vez, conectan con hacinamientos de barracas de madera, sucias, sin electricidad y entre aguas obscuras y un tanto insalubres. El anterior entorno es la base de los niveles más altos, los cuales se alzan en alargadas columnas. Estos últimos niveles ofrecen una mezcla de aspectos modernos y tradicionales dentro de una atmósfera sofisticada: teleféricos repletos de personas (algunas de ellas viajan por fuera, asidos a una barra del vagón), mansiones y edificios coloniales, focos de colores, personajes mexicanos famosos (Frida Kahlo, Cantinflas, Jorge Negrete, Pedro Infante, El Santo, María Félix, Ernesto de la Cruz entre, otros), fiestas, plazas, bares, etc. Los edificios se sitúan tan cerca unos de otros y el número de ellos son notoriamente excesivo que el Mundo de los Muertos resulta ser un territorio abigarrado; congestionado de personas, vehículos, colores, anuncios publicitarios, luces; con alebrijes voladores; etc. Es un mundo que los muertos han adornado con elementos portadores de identidad, traídos desde el lado de la vida; un mundo, además, de marcados contrastes sociales.

De regreso con Miguel (Capítulo 4), en el cementerio de su pueblo, decorado con velas y ofrendas (de forma similar como en algunos pueblos indígenas dentro del estado de Michoacán, México), encuentra a los miembros de su familia que ya han muerto, excepto a su tatarabuela, quien no ha podido "cruzar" (a la Tierra), pues "está atorada en el otro lado" (en el Mundo de los Muertos), según informa un par de tíos gemelos. Todo el grupo va de regreso al Mundo de los Muertos por uno de los puentes, con el fin de ayudar a mamá Imelda.

Es importante destacar algunos signos que se registran en el espacio destinado al paso de un mundo a otro, al final del puente (Capítulo 5). La fachada presenta una arquitectura en piedra labrada de estilo maya, que recuerda al Cuadrángulo de las Monjas, en Uxmal, y la pirámide dedicada al dios Chaac, en Mayapán (ambos en el estado de Yucatán, México). Por encima de aquella estructura, un arreglo de luces rosa mexicano da la bienvenida en español. Las entradas ostentan el letrero "Re-entry" ("Reingreso" o "Entrada" en español). Formadas en fila, las personasesqueleto que están de regreso a su espacio llevan parte de la comida que tomaron de su respectiva 
ofrenda en la Tierra. En un altavoz, a su vez, se da la bienvenida al Mundo de los Muertos y se advierte: "Mantengan sus ofrendas a la mano para el reingreso. Si tienen un problema con su viaje, hay agentes del Departamento de Reuniones Familiares listos para atenderlos". Un oficial de policía le pregunta amablemente a cada uno: “¿Algo que declarar?”, y sella un papel. Al final de la fila, dos hombres, un tanto sospechosos, miran a ambos lados. El primero de ellos, furtivamente, le entrega una botella al segundo. Esta escena pasa fugazmente.

En cuanto a la salida, el procedimiento es un tanto similar. En letrero de los accesos, se lee: "Departures" ("Salidas" en español). Un oficial tiene una pantalla por la que puede escanear, como sucede con los rayos $\mathrm{X}$, el esqueleto de la persona que desea visitar el Mundo de los Vivos. Si algún familiar, en la Tierra, puso la foto de esa persona en el altar, el deudo tendrá permiso de salir, de otro modo, un zumbido alerta la falta y el sujeto tendrá que regresarse. En ese momento, se registra un evento que ilustra lo anteriormente dicho.

Héctor, un músico harapiento y sin reconocimiento durante su vida, trata de salir del Mundo de los Muertos. Sus familiares no lo recordaron en la ofrenda, el escáner no lo registra, así que no puede abandonar ese espacio. El hombre huye en dirección al puente. En cuanto empieza a pisar los pétalos de cempasúchil, Héctor se sume como si estuviera en el agua, de hecho, cuando el nivel de los pétalos le llega al pecho, nada desesperadamente por sobre la superficie anaranjada. De inmediato, un par de oficiales lo detiene. Uno de ellos exclama: "iLo siento, compadre!".

Si revisamos con detenimiento, el par dicotómico encontrado en el apartado anterior, respeto/transgresión, vuelve a presentarse en el actual bajo la forma legalidad/ilegalidad. Con base en ello, en cuanto al cruce divisorio, estamos en condiciones de entender ese sector como una frontera ideológica y una aduana coercitiva, vigilante. Por su importancia dentro de la diégesis, como veremos, podemos considerar ese sitio también como un signo hegemónico y, a la escena completa, como un segundo núcleo semántico.

No resulta infructuoso mencionar que la primera dicotomía de signos hegemónicos (respeto/transgresión) transmite parte de su carga semántica a este segundo mundo textual, por ello es que detectamos en él algunos elementos identitarios presentes en el pueblo de Miguel, esto 
sin importar la transformación de la misma dicotomía (legalidad/ilegalidad) que cumple con otras funciones semiósicas o de significación.

\section{La frontera}

En varios medios de comunicación, la reputación de Coco puede reducirse a la siguiente idea: "Un homenaje a la cultura mexicana". ${ }^{12}$

Retomemos las premisas que expusimos en el segundo apartado de este trabajo: los textos pueden entenderse como elementos testimoniales que concentran ideologías dominantes y/o no dominantes comunes al momento de su producción, por una parte, y, por la otra, las practicas discursivas y/o no-discursivas emitidas por un individuo difícilmente pueden considerarse como "inocentes" o, en todo caso, "neutrales". No debemos perder de vista que, para ambos presupuestos, las circunstancias sociohistóricas que los circundan son altamente determinantes, de tal forma que obligan a asumir una posición crítica.

Una circunstancia sociohistórica que cubre la emergencia de nuestro texto fílmico es la álgida discusión sobre las relaciones entre México y Estados Unidos, hecha, en los últimos años, por parte, principalmente, del gobierno de Donald Trump, misma que ha estigmatizado fuertemente a la primera nación con tonos denigrantes y generalizantes. Por tal razón, la frontera, como signo hegemónico, nos permitirá acceder a estructuras ideológicas insertas en la película.

\section{a) Prototipos y estigmas}

En la frontera, la legalidad queda implícita en el hecho de pasar al Mundo de los Muertos solamente alimentos de las ofrendas y reportarlos. En este caso, los individuos que, sospechosamente, intercambian una botella estarían a punto de infringir las reglas. No es una casualidad, entonces, que se nos muestre ese detalle, aunque sea por breves instantes. Ahora bien, la familia de Miguel, que lo interna es ese mundo escatológico, también incurre en una grave falta, pues está

\footnotetext{
12 Recomendamos las columnas de Coria (2017), Meseguer (2017), Salinas (2018), Ramón (2017), Mena (2016), entre otros muchos.
} 
introduciendo a un ser vivo a un espacio exclusivo para los muertos. Por tal razón, el oficial remite a todo el grupo al Departamento de Reuniones Familiares (Capítulo 5). Es de hacer notar que, en esa oficina, cuelgan dos cuadros que exhiben, a la vez, el territorio mexicano y el sur de Estados Unidos. De alguna manera, estas imágenes funcionan como un anclaje espacial, es decir, un referente geográfico que indica el lugar donde se llevan a cabo las acciones.

En la misma oficina, el niño sostiene una discusión con mamá Imelda, pues ella será la encargada de realizar una especie de hechizo para enviar al chico de vuelta a su pueblo y, de esa forma, él pueda recuperar el retrato de la mujer. El objetivo final reside en que la tatarabuela tenga la facultad de visitar el altar y disfrutar de la ofrenda. Existe, empero, una restricción: Miguel deberá olvidar su deseo de ser músico. El niño se molesta y huye de la oficina en busca de su tatarabuelo y poder así cumplir su deseo (Capítulo 6). Desde ese momento, se organiza un cuerpo de seguridad para buscarlo junto con el resto de familiares y un enorme alebrije volador. En consecuencia, la marca semántica ilegal modeliza al personaje infantil en ese mundo. No debemos dejar pasar que Miguel ha incurrido en una nueva transgresión al no aceptar el mandato de la tía Imelda que, en adición, atenta contra la tradición familiar.

En cuanto a Héctor, pensamos que es más que evidente su comportamiento transgresor. Después de su aprehensión, se reafirma su ilicitud. Aparece en la oficina de un policía quien le hace un recuento de sus delitos cometidos en la frontera. Héctor pregunta si lo que hizo es ilegal. El oficial responde: "Muy ilegal" (Capítulo 6). Héctor lo convence para que lo ayude a "cruzar el puente" esa noche. El oficial le extiende un permiso provisional.

La dicotomía original, respeto/legalidad, es un condensador nocional que, como ya hicimos mención, distribuirá varios de los roles y las acciones de los personajes en el resto del texto, mas las connotaciones ilegalidad y transgresión serán, también como hemos señalado, preponderantes en la frontera y en el Mundo de los Muertos, por ello es que, de la misma manera, consideramos a estas últimas como signos hegemónicos.

Para que exista una transgresión, debe localizarse como antecedente, implícita o explícitamente, una prohibición. La desunión familiar, ofender a la familia, escuchar música, 
dedicarse a otro oficio diferente al de zapatero, no seguir las tradiciones ni obedecer a los mayores son impedimentos centrales que deben observar los Rivera. Miguel, al igual que su tatarabuelo, incurre en cinco de esas seis infracciones (la de no obedecer a los mayores no aplica para este personaje).

Debemos aclarar, empero, que de la Cruz no es el tatarabuelo de Miguel. Ese personaje, en vida, envenenó a Héctor, su mejor amigo; así, se hizo de sus canciones y de su guitarra. Su fama y su capital son, por tanto, ilícitos. La traición, la deslealtad y la mentira, además, como transgresiones, modelizan muchas de sus acciones.

Como hemos visto, la dicotomía que hemos seguido aquí emerge en el punto fronterizo. Con base en ello, dicha oposición tiene como correlatos determinados sintagmas que nos remiten al fenómeno de la migración entre México y Estados Unidos.

La canción Recuérdame, que compusiera Héctor y que posteriormente sería la base del éxito espurio de Ernesto de la Cruz, reproduce algunos marcadores semánticos que refuerzan nuestra afirmación anterior. Revisemos un par de estrofas.

Recuérdame, hoy me tengo que ir, mi amor.

Recuérdame,

No llores por favor.

Te llevo en mi corazón y cerca me tendrás,

A solas yo te cantaré,

Soñando en regresar.

Recuérdame, aunque tenga que emigrar.

Recuérdame.

Si mi guitarra oyes llorar,

Ella con su triste canto te acompañará.

El resto de la letra incide en el hecho de la partida del poeta, misma que deja soledad, tristeza, recuerdo y esperanza, dentro de un ambiente romántico, a la persona amada. (De alguna forma, la canción remite al abandono que hiciera de la Cruz a su familia.) Notemos que el término "emigrar" 
de la segunda estrofa (el original en ingles dice "to travel far"; "viajar lejos" en español) hace referencia al problema que se presenta en la frontera.

Los sintagmas a los que aludimos líneas arriba, los cuales ya hemos transcrito líneas arriba, se refieren a nociones que conforman el fenómeno migratorio mencionado: "cruzar el puente", "el otro lado", “ilegal”, "¿Algo que declarar?”, más el que deviene de la canción, "migrar". A los cinco, por ser tan comunes en varios ambientes sociales (mexicanos y estadounidenses) y por su fácil articulación a dicho fenómeno fronterizo, podríamos considerarlos como sintagmas fijos. ${ }^{13}$

El Mundo de los Muertos, entonces, es el espacio del olvido y el recuerdo. Los difuntos, cuya familia no puso su foto en el altar, corren el riesgo de morir definitivamente. Aquellas personas ocupan las barracas sucias que soportan ese microcosmos. Es el espacio lejano de la migración, de la legalidad y la ilegalidad, de una modernidad con rasgos mexicanos, de la revelación de los secretos. En ese microcosmos, domina, implícitamente, una estructura de poder envolvente: un régimen vigilante de las leyes que no podría asociarse, por todo lo anteriormente expuesto, a un sistema político de características mexicanas. En consecuencia, el enfrentamiento de esas identidades opuestas subraya el conflicto fronterizo, los prototipos mexicanos y sus "vicios". La presencia de los mapas en la oficina del Departamento de Reuniones Familiares nos aclara estas últimas afirmaciones.

Veamos la importancia de una de las acepciones indicadas del término border. La frontera como borde, desde el lado del Mundo de los Muertos, es el final de la vida moderna, con todos sus contrastes, es el final del lugar de los sueños. Después de ese punto, empieza el mundo homogéneo de la tradición y del desorden.

La estrategia de usar como atmósfera envolvente el Día de los Muertos ${ }^{14}$ es parte de la clave del éxito comercial y de la naturalización de las ideologías insertas en el filme. La utilización de ese

\footnotetext{
${ }^{13}$ Un sintagma fijo puede ser una frase o una oración coloquial cuyo uso generalizado y por amplios espacios de tiempo, hace que no sufra variaciones de manera significativa. De esta forma, convoca a un espacio semántico determinado; el ejemplo más sencillo de un sintagma fijo es un dicho.

${ }^{14}$ En un inicio, la película llevaría el título Día de muertos. Por esta razón, la compañía trató de registrar como marca el nombre de esa festividad mexicana.
} 
recurso permite concebir el pensamiento mexicano como mágico, tradicional, atávico y opuesto al racional-científico y moderno.

Ese es uno de los fundamentos de la ideología de "clase" de la burguesía que tiende a separar del poder político y económico a los proletarios, en nombre de una racionalidad menor y de naturaleza diferente.

La historia académica y científica está totalmente permeada por esta idea. Así, describirá a las élites y clases políticas dominantes como estetas, refinadas y cultas, razonables, científicas, mientras el pueblo como grosero, ignorante, supersticioso, "mágico". (Rozat, 2010, p. 75)

En América, esa historia se remonta al siglo XV. Bernal Díaz del Castillo ofrece varios ejemplos al respecto. Tomaremos solamente algunos para ilustrar lo anterior. Después de la batalla contra los tlaxcaltecas, se inicia el pago de tributo a los triunfadores:

[...] fue que luego mandaron llamar todos los adivinos y papas, y otros que echaban suertes, que llamaban tacalnaguas, que son como hechiceros, y dijeron que mirasen por sus adivinanzas y hechizos y suertes qué gente éramos, [...] que ya he dicho otras veces que son cosas malas [los "teules" o dioses], como demonios; [...] porque según pareció, los indios amigos que traíamos de Cempoal les hicieron en creyente que éramos teules e que comíamos corazones de indios, e que las bombardas echaban rayos como caen del cielo, e que el lebrel, que era tigre o león, y que los caballos eran para lancear a los indios cuando los queríamos matar; y les dijeron muchas niñerías. (1983, pp. 169 y 170)

La enorme distancia entre la perspectiva tecnológica de los españoles y la infantil de los indígenas, dominada ésta por juicios sobrenaturales, facilita y justifica la imposición de un nuevo estado de cosas sobre los segundos.

La vida de Miguel, como él mismo dice, está envuelta por un hechizo. La búsqueda de la materialización de su sueño es la urgencia por un cambio de ruta: fama, prestigio, riqueza, todos 
ellos elementos de la Modernidad. Su familia, en contraste, se conforma con continuar la tradición de una vida sostenida por un oficio honesto y nada más. Solamente la participación de signos mágicos y, paradójicamente, antimodernos (alebrijes, hechizos, espíritus, perro guía, etc.) permitirán que el sueño de Miguel sea una realidad.

\section{b) Sueño y realidad}

Dentro de la estructura de cualquier producto artístico, no es atípico encontrarse con rastros ideológicos que, en otros contextos, resultarían altamente contradictorios. La evidente "conciliación" entre elementos modernos y antimodernos en el proyecto de vida de Miguel se funda en un modelo conceptual característico de la vida estadounidense.

El chico cimenta su futuro en una frase común o un sintagma fijo, herencia de su falso tatarabuelo: "iAprovecha tu momento!". De esta forma, la libertad que cada individuo posee, implícita en el sintagma, es el artificio que permite la naturalización de un conflicto entre dos estados de cosas completamente diferentes, a saber, lo moderno y lo antimoderno o tradicional. En consecuencia, el mismo sintagma articula el sueño con la realidad.

Para Miguel, a diferencia de la gran mayoría, el acceso al Mundo de los Muertos es la oportunidad para perseguir y alcanzar sus sueños, muy a pesar de su ilegalidad; la frontera será, además de lo anterior dicho, el acceso que facilita el cambio de identidad: una tradicional (su realidad en la Tierra) por otra liberada de atavismos (la ficcional en el "otro lado"). Así, la quasimágica revelación que experimentara el chico, a los pies de la estatua de Ernesto de la Cruz, contiene el germen de una visión liberal, individualista y, a la vez, fantástica: "en Estados Unidos la ideología predominante es que no debemos estar determinados por nada; debemos poder ser cualquier cosa que deseemos" (Baron-Cohen, 2010, p. 196).

Gracias a la ambigüedad que se inicia desde la frontera, Miguel es tanto un individuo ilegal como un héroe en el Mundo de los Muertos, ya que, como héroe y con base en el método de Vladimir Propp (1999), logra cumplir su meta. Es decir, se convierte en un héroe. Sin olvidar la 
participación de un objeto mágico, la guitarra de Ernesto de la Cruz, que es la "llave" para entrar al Mundo de los Muertos, y un par de aliados: el perro Dante y su verdadero tatarabuelo, Héctor.

El signo hegemónico de la frontera muestra sus dos principales facetas altamente contrastantes, sin embargo, al final del trayecto, el modelo estadounidense es el ojo vigilante (panóptico) que impone la forma de ver las cosas.

La importancia de ese signo hegemónico y de los núcleos semánticos encontrados consiste en distribuir parte de su respectiva carga semántica a lo largo del texto. Dado lo anterior, no resulta una casualidad que la frontera entre los dos mundos sea un condensador nocional en el que aparecen sintagmas fijos y prácticas sociales comunes en la línea que divide a los dos países en la vida real. En adición, ese punto espacial es el límite que distingue fuertemente un mundo de otro, lo cual acentúa las diferencias entre ellos, por ejemplo, pobreza y tradición vs. riqueza y modernidad.

\section{Conclusiones}

Si bien es cierto que partimos de elementos mínimos y dicotómicos para nuestro análisis, lo cual puede verse como una posición reduccionista en extremo, no nos circunscribimos a esas estructuras. Encontramos una gran variedad de posibilidades y esbozamos una relación del texto fílmico con sus circunstancias sociohistóricas de emergencia.

Nuestro breve recorrido ha desmantelado, hasta cierto punto, la concepción comercial de que la película rinde un homenaje a la cultura mexicana; por el contrario, la estructura de la película reproduce, acentúa y ridiculiza prácticas discursivas y no-discursivas "comunes" en algunos ambientes sociales que se asumen como prototípicas; además de la imposición de un modelo ideológico estadounidense como valor prestigioso de vida.

Cuando nos referimos a que existen algunas prácticas sociales discursivas y no-discursivas "comunes" dentro de algunos ambientes sociales mexicanos, podríamos estar cayendo en una situación paradójica, pues haríamos de esas prácticas un prototipo, un constructo indiferenciado. Debemos distinguir entre grupos sociales y prácticas sociales. Los grupos sociales son altamente heterogéneos, cambiantes y complejos, empero, muchas de sus prácticas pueden permanecer por 
largo tiempo vigentes y con pocas variaciones. Esas vigencia y uniformidad son las que nos permiten caracterizarlas de comunes. Por otro lado, el adjetivo "algunos" que califica a ambientes sociales, no es específico, puesto que esas prácticas pueden manifestarse dentro de diferentes ambientes humanos a lo largo de generaciones.

Ahora bien, la imposición de modelos mencionada no es privativa de Coco. Walt Disney lanzó, en 2008, la cinta titulada Una chihuahua de Beverly Hills en la que el tono denigrante es aún mayor que en la actual (ver Morales, 2015). Una de las intenciones textuales de ese filme se reduce a concepciones de orden laboral. Los personajes mexicanos son modelos que se desenvuelven en un ambiente de trabajo que les es "natural": en la jardinería, por su contacto con la tierra. El espacio mexicano es conflictivo, pobre, desordenado, etc. En contraste, Beverly Hills, como enclave metonímico de Estados Unidos, es ejemplo de lujo, opulencia, moda, limpieza, orden, etc. Otro caso similar lo constituyen las series animadas, por ilustrar, de la compañía Warner Brothers, en las que aparece el ratón Speedy Gonzales (sic.) (1953, originalmente) como supuesto exponente del prototipo mexicano.

Muchas de las fuertes declaraciones de Donald Trump contra los/las mexicanos/as y el país ("traficantes de drogas", "el país más peligroso del mundo", "migrantes masivos", "ilegales", "violadores", "pobres", etc.) $)^{15}$ no contrastan, en definitiva, con los prototipos y estigmas que aparecen en Coco, al contrario, las transcribe. Veamos que esas declaraciones son parte de las circunstancias sociohistóricas más cercanas en las que emerge el texto cinematográfico. De hecho, gran parte del éxito electoral de Trump fue, precisa y fundamentalmente, su postura antimexicana. La intención reivindicadora del texto cinematográfico, entonces, ha estado muy lejos de surtir efecto. No tratamos de adoptar una actitud nacionalista o "revanchista" que victimice, idealice y justifique a toda una nación. Después de todo, dentro de la cultura mexicana, existen expresiones denigrantes y prototípicas que se refieren también a un constructo genérico de ciertos grupos

\footnotetext{
${ }^{15}$ El 16 de junio de 2015, en el discurso para el lanzamiento de su candidatura, Trump declara: "Cuando México nos manda gente, no nos mandan a los mejores. Nos mandan gente con un montón de problemas, que nos traen drogas, crimen, violadores..." (BBC Mundo, 2016).
} 
sociales y raciales estadounidenses. Nuestro análisis, en todo caso, persigue localizar estructuras textuales profundas que evidencien ideologías dominantes, las cuales, ya maquilladas, tratan de aparecer como incuestionables y normales dentro de un producto dirigido a una audiencia infantil.

\section{Referencias}

Anderson, B. (1997). Comunidades imaginadas. Reflexiones sobre el origen y la difusión del nacionalismo. México: Fondo de Cultura Económica.

BBC Mundo (2016). 10 frases de Donald Trump sobre México y los mexicanos que 'le ponen picante' a su reunión con Enrique Peña Nieto. https://www.bbc.com/mundo/noticias-america-latina$\underline{37231890}$

Baron-Cohen, S. (2010). La teoría de la concordia en el emparejamiento. En J. Brockman (Ed.), Mente (pp. 193-202), Barcelona: Crítica.

Churchland, P. S. (2012). El cerebro moral. Lo que la neurociencia nos cuenta sobre la moralidad. Barcelona: Paidós.

Coria, J. F. (2017). Coco, un brillante homenaje a México. https://www.eluniversal.com.mx/espectaculos/cine/coco-un-brillante-homenaje-mexico Crespo, M. V. (2014). “Polisemia y política del concepto de frontera”. En H. Crespo, L. G. Morales y M. A. Navarro (coords.), En torno a fronteras e intelectuales. Conceptualizaciones, itinerarios y coyunturas institucionales (pp. 15-27). México: Ítaca-UAEM.

Cros, E. (1986). Literatura, ideología y sociedad. Madrid: Gredos.

Díaz del Castillo, B. (1983). Historia verdadera de la conquista de la Nueva España. México: Patria.

Dorfman, A. y Mattelart, A. (2013). Para leer al Pato Donald: comunicación de masas y colonialismo. México: Siglo XXI.

Mattelart, A. (1979). La cultura como empresa multinacional. México: Era.

Mena, R. (2016). Coco, la nueva película con homenaje a México. http://elhispanonews.com/cocola-nueva-pelicula-con-homenaje-mexico-2/ 
Meseguer, A. (2017). 'Coco', el precioso homenaje de Pixar a México que te emocionará. https://www.lavanguardia.com/cultura/20171129/433267304433/coco-precioso-homenajepixar-mexico.html

Morales, A. (2015). Imágenes e ideología. Ensayos sobre muralismo y cine. Morelia (México): UMSNH.

Propp, V. (1999). (1999). Morfología del cuento. México: Colofón.

Ramón, E. (2017). 'Coco', el homenaje de Disney-Pixar a México en tiempos de Trump. http://www.rtve.es/noticias/20171121/coco-homenaje-disney-pixar-mexico-tiempostrump/1637361.shtml

Rozat, G. (2010). Indios imaginarios e indios reales en los relatos de la Conquista de México. Veracruz (México): Universidad Veracruzana.

Salinas, R. (2018). 'Coco', un homenaje a México. https://www.elfinanciero.com.mx/opinion/ricardo-salinas-pliego/coco-un-homenaje-a$\underline{\text { mexico }}$

Ulrich, L. (2017). Coco [DVD]. Emeryville (USA): Disney-Pixar.

Wodak, R. (2003). “De qué trata el análisis crítico del discurso (ACD). Resumen de su historia, sus conceptos fundamentales y sus desarrollos". En R. Wodak y M. Meyer (comps.), Métodos de análisis crítico del discurso (pp. 17-34). Barcelona: Gedisa. 